\title{
Iron deficiency anemia in the emergency department: over-utilization of red blood cell transfusion and infrequent use of iron supplementation
}

\author{
Jordan Spradbrow*; Yulia Lin, $\mathrm{MD}^{\dagger \S}$; Dominick Shelton, $\mathrm{MD}^{\ddagger \uparrow}$; Jeannie Callum, $\mathrm{MD}^{\dagger \S}$
}

\section{ABSTRACT}

Objectives: Three are no clinical practice guidelines that specifically address the management of patients with iron deficiency anemia (IDA) in the emergency department (ED). The goal of this study was to describe the characteristics of IDA patients who present to the ED, documentation of IDA by emergency physicians, utilization of iron supplementation, and the appropriateness of red blood cell (RBC) transfusions ordered in the ED.

Methods: A retrospective medical chart review was performed of IDA patients who visited the ED of a large tertiary center over a three-month period. Appropriateness of RBC transfusion was determined using a novel algorithm developed by our institution.

Results: Over the study period, there was a $0.3 \%(49 / 14,394)$ prevalence of IDA in the ED. In thirty (30/49; 61\%) patients, IDA was documented by an emergency physician. RBC transfusions were administered to 19 patients; 10 transfusions (53\%) were appropriate, $3(16 \%)$ were appropriate for indication, but more than the required number of units were ordered, and $6(32 \%)$ were inappropriate. Of the patients discharged, one $(1 / 25 ; 4 \%)$ patient received intravenous iron in the ED and 6 of the 11 patients (55\%) that were not already taking oral iron received a prescription at discharge from the ED.

Conclusions: This assessment demonstrated that management of IDA patients presenting to the ED may represent an important knowledge-to-practice gap. It revealed that RBC transfusion may be over-utilized and could be replaced by safer, lower-cost alternatives such as intravenous and oral iron. Guidelines for management of IDA in the ED may be necessary to achieve consistent IDA management and avoid inappropriate use of RBC transfusion.

\section{RÉSUMÉ}

Objectif: II n'existe pas de guide de pratique clinique portant en particulier sur la prise en charge de l'anémie ferriprive (AF) au service des urgences (SU). L'étude décrite ici avait pour but de caractériser les patients atteints d'AF au SU, les notes consignées au dossier par les médecins d'urgence sur I'AF, I'utilisation de la supplémentation martiale et la pertinence des transfusions de culots globulaires (CG) au SU.

Méthode: II s'agit d'un examen rétrospectif de dossiers médicaux de patients atteints $d^{\prime} A F$, qui ont consulté un médecin au SU d'un important centre hospitalier de soins tertiaires sur une période de trois mois. La pertinence des transfusions de CG a été déterminée à l'aide d'un nouvel algorithme élaboré dans l'établissement des auteurs.

Résultats: Durant la période à l'étude, le taux de prévalence de I'AF au SU s'est élevé à 0,3 \% (49/14 394). Dans 30 (30/49; $61 \%)$ cas, I'AF a été consignée par un médecin d'urgence. Dix-neuf patients ont reçu des transfusions de CG : chez 10 (53\%) d'entre eux, les transfusions étaient appropriées; chez $3(16 \%)$ autres, les transfusions étaient appropriées compte tenu de l'indication, mais on a demandé un nombre de culots plus élevé que ce qui était nécessaire; et chez les 6 (32\%) derniers, les transfusions étaient inappropriées. Parmi les patients qui ont obtenu leur congé, $1(1 / 25 ; 4 \%)$ a reçu du fer par voie intraveineuse au SU et, sur les 11 qui ne prenaient pas déjà de fer par voie orale, 6 (55\%) ont reçu une ordonnance au moment du congé du SU.

Conclusions: D'après l'étude, il existerait un important écart entre les connaissances et la pratique relativement à la prise en charge de I'AF au SU. En effet, I'examen a révélé une surutilisation possible des transfusions de CG, traitement qui pourrait être remplacé par des solutions de rechange plus sûres et moins coûteuses telles que l'administration de fer par voie intraveineuse ou par voie orale. II serait donc justifié d'élaborer un guide de pratique clinique sur la prise en charge de l'AF au $\mathrm{SU}$ afin d'assurer une prise en charge uniforme de l'affection et d'éviter I'utilisation inappropriée des transfusions de CG.

Keywords: iron deficiency anemia, emergency department, intravenous iron

From the *Faculty of Arts and Science, †Department of Laboratory Medicine and Pathobiology, and ‡Division of Emergency Medicine, University of Toronto, Toronto, ON; and the §Department of Clinical Pathology and IDepartment of Emergency Medicine, Sunnybrook Health Sciences Centre, Toronto, ON.

Correspondence to: Dr. Jeannie Callum, Director of Transfusion Medicine and Tissue Banks, Department of Clinical Pathology, Sunnybrook Health Sciences Centre, 2075 Bayview Avenue, Room B211, Toronto, ON, M4N3M5; Email: jeannie.callum@sunnybrook.ca 


\section{INTRODUCTION}

Iron deficiency is the most common cause of anemia worldwide. ${ }^{1}$ The extensive consequences of IDA are well-known and include impaired memory, learning and attention span as well as reduced endurance capacity and increased muscle fatigability. ${ }^{2,3}$ Despite both its prevalence and impact, there are few studies of IDA management in adult patients presenting to the emergency department (ED) and no guidelines currently exist for management of IDA in the ED. Studies in pediatric EDs (PED) suggest that IDA is underrecognized and under-treated with iron supplementation in $65 \%$ of cases. ${ }^{4}$ Studies of adult hospitalized patients suggest that inappropriate use of red blood cell (RBC) transfusion for IDA occurs in one in four patients, which not only unnecessarily exposes patients to risks of transfusion but is economically wasteful. ${ }^{5-7}$ The importance of reducing inappropriate transfusion for IDA is recognized at a national level. In support of the American Board of Internal Medicine Choosing Wisely initiative to reduce the overuse of common medical procedures, the American Association of Blood Banks (AABB) released five statements to promote better blood management. ${ }^{8}$ One of these statements was, "Don't transfuse red blood cells for iron deficiency without hemodynamic instability". 8

The primary objective of this study was to describe the management of adult IDA patients presenting to the ED including, documentation of IDA by emergency physicians and use of intravenous (IV) iron, oral iron and RBC transfusion. Our second objective was to assess the appropriateness of RBC transfusions ordered by emergency physicians for IDA patients in the ED.

\section{METHODS}

\section{Identification of patients}

A retrospective chart review of patients presenting to the ED of a large tertiary care center in Toronto, Canada was conducted over three months from August 1 to October 31, 2013. Patients at risk for IDA were identified by screening the hospital's ED database for diagnoses at high risk of IDA. These diagnoses included: anemia unspecified, transfusion, bleeding unspecified, dysfunctional uterine bleeding, menorrhagia, post-menopausal bleeding, vaginal bleeding, fibroids, hematuria, gastrointestinal (GI) bleeding, and oral bleeding. IDA was defined based on laboratory investigations at time of presentation to the ED: (1) hemoglobin $<120 \mathrm{~g} / \mathrm{L}$ for females or $130 \mathrm{~g} / \mathrm{L}$ for males $^{9}$, (2) mean corpuscular volume $(\mathrm{MCV})<75 \mathrm{fL}$ (with previously normal MCV present) or serum ferritin $<30 \mu \mathrm{g} / \mathrm{L}$ within six months of ED visit. Use of a serum ferritin threshold of $<30 \mathrm{ug} / \mathrm{L}$ and an $\mathrm{MCV}$ threshold of $\leq 75 \mathrm{ug} / \mathrm{L}$ to detect IDA is supported in the literature. ${ }^{10,11}$ Guyatt et al. conducted a systematic review to determine the diagnostic value of common laboratory tests used in the diagnosis of IDA. They found that the predictive values or areas under the receiver operating characteristic (ROC) curves for serum ferritin (ROC $0.95, p<0.001$ ) and MCV (ROC $0.77, p<0.001)$ were significantly more powerful than transferrin saturation (ROC: 0.74 ) and absolute red cell distribution (ROC: 0.62). The authors further found that $\mathrm{MCV}$ values between 70-75 $\mathrm{fL}$ were associated with a likelihood ratio (LR) (indicates how much the odds of a disease increase when a test is positive) of 3.33 and serum ferritin values between $15-25 \mu \mathrm{g} / \mathrm{L}$ were associated with an LR of $8.83 .{ }^{10}$ Additionally, Goodnough et al. calculated that a ferritin of $\leq 30 \mu \mathrm{g} / \mathrm{L}$, had a sensitivity of $92 \%$ for IDA, with a positive predictive value of $83 \% .{ }^{11}$ All patients meeting these criteria were considered to have IDA and were included in the study. The study was approved by the institutional research ethics board.

\section{Data collection}

Data collected included demographic features, referral information, admission and discharge details, laboratory results, and treatment and follow-up information. Laboratory results collected included hemoglobin, MCV, red cell distribution width, serum ferritin, and transferrin saturation. Median values for ferritin and transferrin saturation were calculated using values either at time of presentation to ED, within six months prior to ED visit, or within course of hospital admission (value closest to ED visit, but before intravenous (IV) iron/transfusion, used if multiple measurements found). All other medians were calculated using lab values at presentation to the ED. RBC transfusions ordered by emergency physicians in the ED were documented. Since patients admitted to hospital may receive iron therapy during the course of their admission and given that our primary interest was in the practice of emergency physicians, iron supplementation ordered by 
emergency physicians was noted only for patients discharged from the ED.

\section{Documentation and management of IDA}

Documentation of IDA by an emergency physician was noted if any of the following were found in the ED medical chart: diagnosis of IDA, notation of a low ferritin or low MCV, past medical history of IDA, the patient was noted to be already taking oral iron, a ferritin was ordered in the ED, IV iron was ordered in the $\mathrm{ED}$, or oral iron was written in the discharge plan.

Utilization of iron supplementation and RBC transfusion practice in the ED was compared to the proposed algorithm for management of IDA in the ED shown in Figure 1. Recommendations for use of RBC transfusion were adapted from institutional guidelines, clinical practice guidelines from the AABB, supporting randomized clinical trials and systematic reviews regarding the efficacy of IV iron and its association with reduced risk of requirement for transfusion. ${ }^{12-15}$ If an emergency physician ordered a transfusion according to the algorithm, the transfusion was considered appropriate. Recommendations for use of iron supplementation were adapted from institutional guidelines and are consistent with published guidelines from professional societies. ${ }^{16,17}$ Given the lack of robust scientific data regarding indications for iron therapy, in comparison to RBC transfusion, appropriateness of iron supplementation usage was not assessed. The algorithm was used only to identify candidates for IV and oral iron.

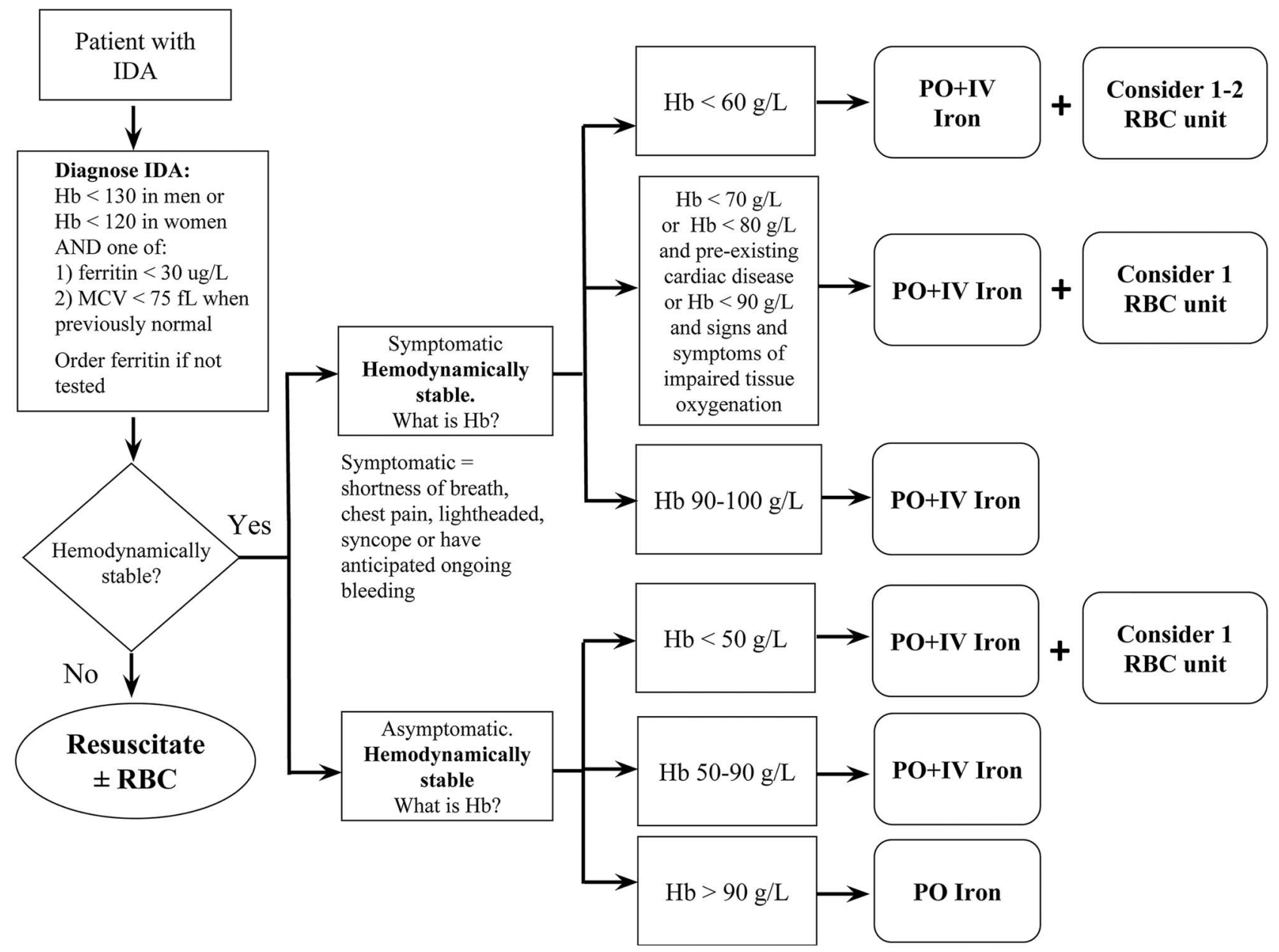

Figure 1. Optimal clinical practice recommendations for management of hemodynamically stable patients with iron deficiency anemia (IDA) in the emergency department (ED) using red blood cell (RBC) transfusion, intravenous (IV) iron or oral (PO) iron. Hemodynamically stable patients were defined as those without need for active resuscitation to keep urine output $>0.5 \mathrm{~mL} / \mathrm{kg}$ per min, systolic arterial pressure $>90 \mathrm{~mm} \mathrm{Hg}$, and heart rate $<120$ beats/minutes. This algorithm was used to assess appropriateness of RBC transfusion in the ED and candidacy for iron supplementation. 


\section{Statistical analysis}

Categorical data were reported as frequencies and proportions, whereas continuous variables were reported as medians with interquartile ranges (IQR) given that most data were skewed. Patients were divided by admission status for comparison purposes.

\section{RESULTS}

\section{Demographic and baseline features}

Between August 1 and October 31, 2013, there were a total of 14,394 patient visits to the ED. Of these, 408 patients had diagnoses placing them at risk of IDA. Forty-nine of these patients met our definition of IDA, for a $0.3 \%$ overall prevalence in the ED over three months and $12 \%$ prevalence of IDA among ED patients at an increased risk of IDA. Twenty-two of these patients were admitted to hospital. Twenty-seven patients were discharged; 25 were cared for solely by emergency physicians and two experienced collaborative care (emergency physician and gynecology consult service). Baseline demographics, divided by admission status, are shown in Table 1 . The majority (34/49; 69\%) of patients were female and the median age was 60 years (IQR: 43-83). Approximately half (26/49; 53\%) of the patients were referred to the ED by a primary care

\begin{tabular}{|c|c|c|c|}
\hline & $\begin{array}{c}\text { Total } \\
\text { No. }(\%) \\
(n=49)\end{array}$ & $\begin{array}{c}\text { Admitted } \\
\text { No. }(\%) \\
(n=22)\end{array}$ & $\begin{array}{c}\text { Discharged } \\
\text { No. (\%) } \\
(n=27)\end{array}$ \\
\hline \multicolumn{4}{|l|}{ Age } \\
\hline $18-35$ & $7(14)$ & 2 (9) & $5(19)$ \\
\hline $36-65$ & $21(43)$ & $5(23)$ & $16(59)$ \\
\hline $66-80$ & $7(14)$ & $4(18)$ & $3(11)$ \\
\hline$\geq 80$ & $14(29)$ & $11(50)$ & $3(11)$ \\
\hline \multicolumn{4}{|l|}{ Gender } \\
\hline Female & $34(69)$ & $9(41)$ & $25(93)$ \\
\hline Male & $15(31)$ & $13(59)$ & $2(7)$ \\
\hline $\begin{array}{l}\text { Referral to ED from primary } \\
\text { care physician }\end{array}$ & $26(53)$ & $9(41)$ & $17(63)$ \\
\hline \multicolumn{4}{|c|}{ Diagnoses at presentation to ED } \\
\hline Unspecified anemia & $20(41)$ & $11(50)$ & $9(33)$ \\
\hline Gynecologic & $14(29)$ & $1(5)$ & $13(48)$ \\
\hline GI Bleed & $13(27)$ & $10(45)$ & $3(11)$ \\
\hline Bleeding (other) & $1(2)$ & 0 & $1(4)$ \\
\hline Transfusion & $1(2)$ & 0 & $1(4)$ \\
\hline
\end{tabular}

physician most commonly for a low hemoglobin (18/26; $69 \%)$, but also for anemia symptoms $(3 / 26 ; 12 \%)$, iron deficiency $(3 / 26 ; 12 \%)$, and request for transfusion $(2 / 26 ; 8 \%)$. Compared to the admitted patients, those discharged from the ED were more commonly female (93\% v. $41 \%$ ), younger (median 48 v. 81 years), referred by their primary care physicians $(63 \%$ v. $41 \%)$ and presenting with gynecologic diagnoses (48\% v. $5 \%$ ).

Median laboratory parameters most relevant to IDA diagnoses are displayed in Table 2. The discharged patients showed a lesser severity of anemia compared to those admitted (median hemoglobin: $84 \mathrm{~g} / \mathrm{L}$ v. $74 \mathrm{~g} / \mathrm{L}$ ) and had lower MCV and ferritin levels (median MCV: $69 \mathrm{fL}$ v. $78 \mathrm{fL}$; ferritin: $6 \mu \mathrm{g} / \mathrm{L} \mathrm{v.} 15 \mu \mathrm{g} / \mathrm{L}$ ).

\section{Documentation of IDA and follow-up}

In thirty of 49 patients (61\%), there was documentation of investigation or management of IDA in the medical chart. This occurred more frequently in the discharged patients compared to those admitted $(20 / 27 ; 74 \% \mathrm{v}$. $10 / 22 ; 45 \%)$. In those patients where IDA was documented, it was frequently in the form of a noted past medical history of IDA (discharged: 15/27; 55\%, admitted: $5 / 22 ; 23 \%)$.

Sixteen $(19 / 27 ; 70 \%)$ of the discharged patients had follow-up care arranged by an emergency physician, commonly with gynecology $(9 / 19 ; 47 \%)$, but also, gastroenterology $(4 / 19 ; 21 \%)$, hematology $(3 / 19 ; 16 \%)$, oncology $(2 / 19 ; 11 \%)$, and internal medicine $(1 / 19$; $5 \%)$.

\section{Use of RBC transfusion}

Nineteen of the 49 IDA patients received a RBC transfusion in the ED, representing $11 \%$ of all transfusions given in the ED over the study period (19/171 RBC transfusions given in ED from August 1 to October 31, 2013). Table 3 displays the proportion of patients transfused, stratified by hemoglobin levels. Of the 19 transfused patients, $10(53 \%)$ received a transfusion that was appropriate for indication and dose, $3(16 \%)$ received a transfusion that was appropriate for indication but too many $\mathrm{RBC}$ units were transfused (mean number of inappropriate unit: 2.3 (range: 2-3) v. appropriate units: 1.2 (range: 12)) and 6 (32\%) were inappropriate. A total of eleven (11/26; $42 \%$ ) units of RBCs were inappropriate. 


\begin{tabular}{|c|c|c|c|c|c|c|}
\hline & \multicolumn{2}{|c|}{ All Patients } & \multicolumn{2}{|c|}{ Admitted Patients } & \multicolumn{2}{|c|}{ Discharged Patients } \\
\hline & $\mathrm{n}$ & median (IQR) & $\mathrm{n}$ & median (IQR) & $\mathrm{n}$ & median (IOR) \\
\hline Hemoglobin (g/L) & 49 & $74(63-92)$ & 22 & $74(59-91)$ & 27 & $84(63-99)$ \\
\hline Mean Corpuscular Volume (fL) & 49 & $71(68-84)$ & 22 & $78(70-88)$ & 27 & $69(63-81)$ \\
\hline Red Cell Distribution Width & 49 & $19(17-21)$ & 22 & $19(17-20)$ & 27 & $19(16-21)$ \\
\hline Ferritin $(\mu \mathrm{g} / \mathrm{dL})^{*}$ & 46 & $10(5-15)$ & 21 & $15(10-17)$ & 25 & $6(4-10)$ \\
\hline Transferrin Saturation* & 25 & $0.07(0.03-0.11)$ & 13 & $0.08(0.04-0.27)$ & 12 & $0.05(0.02-0.08)$ \\
\hline
\end{tabular}

Table 3. Proportion of patients transfused in the ED distributed by hemoglobin levels

\begin{tabular}{|c|c|c|c|c|c|c|}
\hline Hemoglobin (g/L) & $\begin{array}{c}\text { Total } \\
\text { (n) }\end{array}$ & n (\%) Transfused & $\begin{array}{c}\text { Admitted } \\
\text { (n) }\end{array}$ & n (\%) Transfused & $\begin{array}{c}\text { Discharged } \\
\text { (n) }\end{array}$ & n (\%) Transfused \\
\hline$<50$ & 2 & $2(100)$ & 2 & $2(100)$ & 0 & 0 \\
\hline $50-59$ & 6 & $4(67)$ & 4 & $2(50)$ & 2 & $2(100)$ \\
\hline $60-69$ & 12 & $9(75)$ & 5 & $5(100)$ & 7 & $4(57)$ \\
\hline $70-79$ & 8 & $2(25)$ & 4 & $1(25)$ & 4 & $1(25)$ \\
\hline$\geq 80$ & 21 & $2(10)$ & 7 & $1(14)$ & 14 & $1(7)$ \\
\hline
\end{tabular}

\section{Use of iron supplementation:}

Out of the 25 discharged patients exclusively managed by emergency physicians, only one (4\%) patient received IV iron, six (24\%) patients were commenced on oral iron and fourteen (56\%) patients were already taking oral iron at time of presentation to the ED. Given their severity of anemia, $16(16 / 25 ; 64 \%)$ patients were considered candidates for IV iron according to the proposed algorithm presented in Figure 1, and $11(11 / 25 ; 44 \%)$ were candidates for oral iron supplementation.

\section{DISCUSSION}

This retrospective review demonstrated that IDA is a presenting problem in the ED with heterogeneous management, namely, with infrequent use of iron supplementation and over-utilization of RBC transfusion.

Out of 49 patients, $61 \%$ had documentation of IDA in their medical chart by an emergency physician. However, much of this documentation was accredited to prior diagnoses of IDA, made before the patient presented to the ED. Although there are several appropriate reasons for lack of IDA documentation, it is possible that this observation may signify underrecognition. Berard et al. found in a survey of
111 pediatric emergency physicians that $96 \%$ did not routinely screen blood work for IDA in at-risk children and infants. ${ }^{18}$ Another reason for a lack of documentation of IDA may be that emergency physicians do not feel IDA diagnosis falls within their mandate. This was supported by Berard et al. who noted that $67 \%$ of surveyed physicians did not feel an IDA diagnosis was their responsibility. ${ }^{18}$ Another explanation may be that complete blood count (CBC) indices relevant to IDA are underutilized. Pusic et al., upon finding $65 \%$ of low MCVs (<70 fL) were unrecognized, proposed that time-pressured emergency physicians are subject to adaptive heuristics prompting focus on commonly used diagnostic CBC lab values, and not on $M C V$ which can be highly suggestive of IDA. ${ }^{4}$ Since the majority of patients assessed in the ED either have a CBC performed at presentation $(100 \%$ of patients in our study) or are referred to the ED from a family physician with a CBC previously completed $(53 \%$ of patients in our study), the MCV may represent an inexpensive opportunity to screen for IDA in the ED.

Our results indicated considerable heterogeneity of approaches taken to manage IDA in the ED, namely, infrequent use of parenteral and/or oral iron supplementation. In our study, $4 \%$ of patients were administered IV iron and $24 \%$ were commenced on oral iron at ED discharge. These findings are comparable to PED 
studies, wherein use of iron therapy is low ${ }^{4,19}$. The application of an algorithm or guidelines for management of IDA in the ED, such as the one proposed in this study, may aid in reducing this variability. Applying the algorithm to the audited population indicated that a much larger proportion of discharged patients were candidates for IV iron (64\%) and oral iron (44\%) compared to the proportion who received them. We raise this discrepancy as a potential missed opportunity for provision of iron therapy in the ED. There may be clinical reluctance to use IV iron because emergency physicians may feel that iron therapy will interfere with further diagnostic work-up of anemia or unawareness that IV iron can be administered in the ED, both of which have been observed anecdotally at our institution. In regard to further anemia work-up, a ferritin level should be measured prior to administering IV iron, as a measurement within 48 hours after IV iron administration will be falsely elevated. ${ }^{20}$ Low use of IV iron may also be related to the risk of anaphylaxis associated with older, high-dose iron dextran formulations. However, newer formulations have been available for decades and largely alleviate this problem. A large retrospective review looked at risk of anaphylaxis among 680,000 non-dialysis patients receiving both iron dextran and non-dextran IV iron formulations, and found that risk of anaphylaxis in the non-dextran group was less than half the risk of anaphylaxis in the iron dextran group $\left(68 / 100,000\right.$ v. 24/100,000). ${ }^{21}$ Other commonly raised concerns regarding IV iron include promotion of infection by supplying free iron to pathogenic bacteria or promotion of atherosclerosis by generating oxidative stress. However, these concerns are poorly supported. A recent systematic review and meta-analysis analyzed 103 randomized control trials evaluating IV iron and found no increased risk of infection regardless of compound, comparator or indication (RR, 1.17; CI 0.83-1.65) or increased risk of cardiovascular adverse events (RR, 0.99 CI $0.83-1.17$ ). ${ }^{22}$

It is important to emphasize that blood transfusion, in absence of hemodynamic instability, concerning symptoms (syncope, chest pain, shortness of breath or presyncope), or patient refusal is an inappropriate management strategy for IDA. While transiently elevating hemoglobin levels, transfusion potentially neglects underlying mechanisms causing anemia. ${ }^{8}$ In our study, $32 \%$ of transfusions given to IDA patients were inappropriate, and $16 \%$ of transfusions were excessive in amount of units. Of note, restrictive transfusion strategies were practiced by some emergency physicians given $43 \%$ of patients with a hemoglobin between $60-69 \mathrm{~g} / \mathrm{L}$ were not transfused. Overtransfusion for IDA is a common theme found in the literature. ${ }^{5,23,24}$ One study assessing adult ED transfusion practice determined 11 of 13 transfusions for IDA were given inappropriately in place of iron supplementation. ${ }^{24}$ In adult internal medicine patients, Saxena et al. estimated that one-quarter of transfusions for IDA were inappropriate, given without anemia investigation and despite stable clinical status. ${ }^{5}$ Over-transfusion for IDA may indicate a lack of understanding of the difference between acute and chronic anemia and the biological compensations which occur in the latter. IDA produces chronic anemia that does not need immediate correction with transfusion. Unlike cases of acute blood loss which may lead to hemodynamic instability and poor oxygen delivery, chronic anemia is not associated with hypovolemia and oxygen delivery is enabled by a right shift in the oxygen dissociation curve, facilitated by increased 2,3-diphosphoglycerate. ${ }^{8}$ There is even evidence that over transfusion may be harmful in the setting of acute blood loss. A recent 2010 trial by Villanueva et al. found that restrictive transfusion strategies significantly reduced risk of re-bleeding and length of stay for patients with gastrointestinal bleeding. The authors suggested that use of transfusion should be limited in these patients given that transfusion may counteract the vasoconstrictive response caused by hypovolemia in the setting of an acute bleed. ${ }^{25}$

Unnecessary treatment with RBCs and limited use of more appropriate iron replacement therapies in the ED can have a high impact for both the patient and at a broader ED/hospital-wide level. Unnecessary transfusion exposes patients to risks, including alloimmunization, which in women of child bearing age (14\% of our study population) can increase the risk of hemolytic disease of the newborn in future pregnancies. ${ }^{26} \mathrm{IV}$ and oral iron are also economical iron replacement strategies. IV iron infusion is estimated to cost $\$ 200$ per $500 \mathrm{mg}$ infusion and oral iron can cost as little as $\$ 0.05$ per tablet, both significantly less than the accumulative cost of $\$ 761$ per unit of RBCs. ${ }^{27}$ Additionally, the ED length of stay for patients receiving RBC transfusion is six times longer than for patients treated with IV iron, impacting patient flow in the ED.

It is important to acknowledge that identifying patients with IDA in the ED is a challenge. Our study found only a $0.3 \%$ prevalence of IDA in the ED over a 
three-month period. However, this does begin to suggest some key clinical features that might be helpful to the clinician in increasing the index of suspicion for patients with IDA. The prevalence of IDA was much higher in discharged patients with gynecologic diagnoses (48\%). Furthermore, $63 \%$ of the discharged IDA patients were referred to the ED by their family physician often for low hemoglobin or transfusion, which may be another clinical flag where screening of IDA would be high yield. These highlighted clinical features may also serve as starting points for future study and subsequent interventions to broadly address IDA management. The large proportion of referrals to the ED found in this study may indicate untimely recognition of IDA and unfamiliarity with IDA management or transfusion indications at the primary care level. Educational intervention targeting IDA diagnosis management at the primary care level may help prevent these referrals to the ED. Our study also identified a considerable proportion (29\%) of patients over 80 years of age with IDA. Previous research indicates only onethird of anemic elderly patients presenting to hospital undergo testing to determine if iron deficiency is a contributing factor. ${ }^{28}$ It is important that anemia investigations which may be initiated in the ED, also occurs in these patients given that iron deficiency is the second most common cause of anemia in the elderly. ${ }^{29}$

Implementation of an algorithm for the management of IDA in the ED may resolve the variability in practice observed in this study. We plan to use the results generated by this study to design a quality improvement (QI) initiative with the aim of optimizing management of IDA in the ED, specifically, appropriate use of RBC transfusion. The proposed QI project will involve the implementation of the algorithm and an IDA toolkit (IV iron patient pamphlet, physician order for IV iron, oral iron prescription, and discharge letter to primary care physician) in the EDs of an academic and community hospital. This QI study will determine whether use of an algorithm in a time-sensitive environment like the $\mathrm{ED}$ is feasible and whether implementing guidelines for the management of IDA in the ED can serve to achieve consistent, quality care for IDA patients.

There are several limitations to this study. First, we only screened patients at high risk for iron deficiency and used strict criteria to define IDA, therefore it is possible that our study may substantially underestimate the prevalence of IDA in ED patients by including only the most severe cases. Second, given the nature of a retrospective chart review, our study is subject to documentation bias. Emergency physicians may have considered IDA or acknowledged a previously performed ferritin level but not recorded it in the medical chart, making it difficult to accurately assess documentation and recognition of IDA. Furthermore, IDA is not an emergency in itself and thus there may be appropriate reasons not to start iron therapy in the $\mathrm{ED}$, for example, due to the patient's wishes or transfer to the primary care team for further investigation. Additionally, generalizability of our study may be limited given this was a single center audit with a small sample size. Although given previous studies, it is expected that similar practice improvements would have benefit in other jurisdictions.

\section{CONCLUSIONS}

This retrospective chart review revealed that IDA was managed variably in the ED, including over use of RBC transfusion and infrequent use of safer, cheaper, and more effective alternative treatments, such as intravenous and oral iron. Introducing guidelines for management of IDA in the ED, such as the algorithm used in this study, may improve consistency and quality of care for IDA patients presenting to the ED.

Competing Interest: This research received no specific grant funding from any agency, commercial or not-for-profit sectors. No conflict of interest declared.

\section{REFERENCES}

1. Pasricha SR. Should we screen for iron deficiency anaemia? A review of the evidence and recent recommendations. Pathology 2012;44(2):139-47.

2. Lamanca JJ, Haymes EM. Effects of low ferritin concentration on endurance performance. Int 7 Sport Nutr 1992;2(4):376-85.

3. Murray-Kolb LE, Beard JL. Iron treatment normalizes cognitive functioning in young adult women. Am 7 Clin Nutr 2007;85(3):778-87.

4. Pusic MV, Dawyduk BJ, Mitchell D. Opportunistic screening for iron-deficiency in 6-36 month old children presenting to the Paediatric Emergency Department. $B M C$ Pediatr 2005;5:42.

5. Saxena S, Rabinowitz AP, Johnson C, et al. Iron-deficiency anemia: a medically treatable chronic anemia as a model for transfusion overuse. Am 7 Med 1993;94(2):120-4.

6. Rohde JM, Dimcheff DE, Blumberg N, et al. Health careassociated infection after red blood cell transfusion: a systematic review and meta-analysis. $7 A M A$ 2014; 311(13):1317-26. 
7. Salpeter SR, Buckley JS, Chatterjee S. Impact of more restrictive blood transfusion strategies on clinical outcomes: a meta-analysis and systematic review. Am 7 Med 2014; 127(2):124-31.e3.

8. Callum JL, Waters JH, Shaz BH, et al. The AABB recommendations for the Choosing Wisely campaign of the American Board of Internal Medicine: AABB Choosing Wisely Campaign. Transfusion 2014;54(9):2344-52.

9. World Health Organization. Hemoglobin concentrations for the diagnosis of anemia and assessment of severity. Available at http://www.who.int/vmnis/indicators/haemoglobin.pdf (acessed January 15, 2016).

10. Guyatt GH, Oxman $\mathrm{AD}$, Ali M, et al. Laboratory diagnosis of iron-deficiency anemia: an overview. 7 Gen Intern Med 1992;7(2):145-53.

11. Goodnough LT, Elizabeta N, Tomas G. Detection, evaluation, and management of iron-restricted erythropoiesis. Blood 2010;116(23):4754-61.

12. Carson JL, Grossman BJ, Kleinman S, et al. Red blood cell transfusion: a clinical practice guideline from the AABB*. Ann Intern Med 2012;157(1):49-58.

13. Litton E., Xiao J, Ho KM. Safety and efficacy of intravenous iron therapy in reducing requirement for allogeneic blood transfusion: systematic review and meta-analysis of randomised clinical trials. BMJ 2013;347:f4822.

14. Muñoz M, Breymann C, Garcia-Erce JA. Efficacy and safety of intravenous iron therapy as an alternative/adjunct to allogeneic blood transfusion. Vox Sang 2008;94(3):172-83.

15. Prick BW, Steegers EA, Jansen AJ, et al. Well being of obstetric patients on minimal blood transfusions (WOMB trial). BMC Pregnancy Childbirth 2010;10:83.

16. Sinclair M, Andrews J, Sheppard S, et al. Gastroenterological Society of Australia (GESA): Iron deficiency. Available at: http://www.gesa.org.au/files/editor_upload/ File/Professional/Iron_def.pdf. 2011 (accessed October 21, 2016).

17. BC Guidelines. Iron deficiency-Investigation and management. Available at: http://www2.gov.bc.ca/gov/content/ health/practitioner-professional-resources/bc-guidelines/irondeficiency (accessed October 21, 2016).
18. Berard R, Matsui D, Lynch T. Screening for iron deficiency anemia in at risk children in the pediatric emergency department: a survey of Canadian pediatric emergency department physicians. Pediatr Emerg Care 2007;23(5): 281-4.

19. Mekky M, Jasuja M, Parkin PC. Moderate and severe microcytic anemia in the emergency department: indicators of care. Clin Ped 2009;48(9):902-3.

20. Hayat A. Safety issues with intravenous iron products in the management of anemia in chronic kidney disease. Clin Med Res 2008;6(3-4):93-102.

21. Wang C, Graham DJ, Kane RC, et al. Comparative risk of anaphylactic reactions associated with intravenous iron products. FAMA 2015;314(19):2062-8.

22. Avni T, Bieber A, Grossman A, et al. The safety of intravenous iron preparations: systematic review and metaanalysis. Mayo Clin Proc 2015;90(1):12-23.

23. Ahmad I, Gibson PR. Management of iron deficiency in patients admitted to hospital: time for a rethink of treatment principles. Intern Med 7 2006;36(6):347-54.

24. Froom P, Griikshtas R, Havis R, et al. Adding a caveat to the urgent clinical notification of anaemia does not reduce inappropriate emergency room referral rates. Clin Lab Haem 2003;25(3):149-53.

25. Villanueva C, Colomo A, Bosch A, et al. Transfusion strategies for acute upper gastrointestinal bleeding. $N$ Engl 7 Med 2013;368(1):11-21.

26. Zalpuri S, Zwaginga JJ, van der Bom JG. Risk Factors for Alloimmunisation after red blood Cell Transfusions (R-FACT): a case cohort study. BMF Open 2012;2(3): e001150.

27. Shander A, Hoffman A, Ozawa S, et al. Activity-based costs of blood transfusion in surgical patients at four hospitals. Transfusion 2010;50(4):753-65.

28. Rohrig G, Klossok W, Becker I, et al. Prevalence of anemia among elderly patients in an emergency room setting. Eur Geriatri Med 2014;5(1):3-7.

29. Mukhopadhyay D, Mohanaruban K. Iron deficiency anemia in older people: investigation, management and treatment. Age Ageing 2002;31(2):87-91. 